Article

\title{
Successful High-Dosage Monotherapy of Tigecycline in a Multidrug-Resistant Klebsiella pneumoniae Pneumonia-Septicemia Model in Rats
}

\author{
Hessel Van der Weide ${ }^{\circledR}$, Marian T. Ten Kate, Denise M. C. Vermeulen-de Jongh, \\ Aart Van der Meijden, Rixt A. Wijma, Stefan A. Boers, Mireille Van Westreenen, John P. Hays, \\ Wil H. F. Goessens * and Irma A. J. M. Bakker-Woudenberg \\ Department of Medical Microbiology \& Infectious Diseases, Erasmus University Medical Center \\ Rotterdam (Erasmus MC), 3015 GD Rotterdam, The Netherlands; hessel.vanderweide@gmail.com (H.V.d.W.); \\ m.tenkate@erasmusmc.nl (M.T.T.K.); d.m.c.dejongh@hotmail.com (D.M.C.V.-d.J.); \\ a.vandermeijden@erasmusmc.nl (A.V.d.M.); r.wijma@erasmusmc.nl (R.A.W.); stefan_boers@me.com (S.A.B.); \\ m.vanwestreenen@erasmusmc.nl (M.V.W.); j.hays@erasmusmc.nl (J.P.H.); \\ i.bakker-woudenberg@erasmusmc.nl (I.A.J.M.B.-W.) \\ * Correspondence: w.goessens@erasmusmc.nl; Tel.: +31-10-703-6171
}

Received: 6 February 2020; Accepted: 27 February 2020; Published: 3 March 2020

check for updates

\begin{abstract}
Background: Recent scientific reports on the use of high dose tigecycline monotherapy as a "drug of last resort" warrant further research into the use of this regimen for the treatment of severe multidrug-resistant, Gram-negative bacterial infections. In the current study, the therapeutic efficacy of tigecycline monotherapy was investigated and compared to meropenem monotherapy in a newly developed rat model of fatal lobar pneumonia-septicemia. Methods: A Klebsiella pneumoniae producing extended-spectrum $\beta$-lactamase (ESBL) and an isogenic variant producing K. pneumoniae carbapenemase (KPC) were used in the study. Both strains were tested for their in vitro antibiotic susceptibility and used to induce pneumonia-septicemia in rats, which was characterized using disease progression parameters. Therapy with tigecycline or meropenem was initiated at the moment that rats suffered from progressive infection and was administered 12-hourly over 10 days. The pharmacokinetics of meropenem were determined in infected rats. Results: In rats with ESBL pneumonia-septicemia, the minimum dosage of meropenem achieving survival of all rats was $25 \mathrm{mg} / \mathrm{kg} /$ day. However, in rats with KPC pneumonia-septicemia, this meropenem dosage was unsuccessful. In contrast, all rats with KPC pneumonia-septicemia were successfully cured by administration of high-dose tigecycline monotherapy of $25 \mathrm{mg} / \mathrm{kg} /$ day (i.e., the minimum tigecycline dosage achieving $100 \%$ survival of rats with ESBL pneumonia-septicemia in a previous study). Conclusions: The current study supports recent literature recommending high-dose tigecycline as a last resort regimen for the treatment of severe multidrug-resistant bacterial infections. The use of ESBL- and KPC-producing K. pneumoniae strains in the current rat model of pneumonia-septicemia enables further investigation, helping provide supporting data for follow-up clinical trials in patients suffering from severe multidrug-resistant bacterial respiratory infections.
\end{abstract}

Keywords: tigecycline; meropenem; pneumonia; septicemia; Klebsiella pneumoniae; antibiotic resistance

\section{Introduction}

Recent data from the U.S. indicate that Gram-negative bacteria are responsible for more than $30 \%$ of hospital-acquired infections [1]. A complicating factor in the treatment of infections caused by Gram-negative bacteria is the worldwide increase of antimicrobial resistance. In particular, Gram-negative bacteria resistant to carbapenem antibiotics—due to the presence of plasmid-mediated 
multidrug resistance, such as with extended-spectrum $\beta$-lactamase (ESBL) or Klebsiella pneumoniae carbapenemase (KPC) — can no longer be effectively treated with $\beta$-lactam antibiotics and tend to be susceptible only to "drugs of last resort" [2,3].

Tigecycline (an antibiotic belonging to the class of glycylcyclines) is one such drug of last resort, although resistance to tigecycline has been reported [4]. Further, although the United States Food and Drug Administration (FDA) issued a warning in 2013 relating to an apparent increased death rate during antibiotic treatment using tigecycline (loading dose of $100 \mathrm{mg}$ followed by $50 \mathrm{mg}$ every 12 h) [5], multiple studies have suggested that using a high dose of tigecycline could actually improve the outcome in comparison to conventional dosing [6,7]. Additionally, the European Committee on Antimicrobial Susceptibility Testing (EUCAST) has recently recommended the use of high-dosage tigecycline treatment in seriously ill patients infected with multidrug-resistant bacteria [8]. As well as dosing issues, another debate about the role of tigecycline involves its use in monotherapy as opposed to combination therapy, particularly in the treatment of multidrug-resistant, Gram-negative bacterial infections. This issue is complicated by the fact that comparative clinical efficacy studies into tigecycline are complex, involving differing patient characteristics, various combinations of antibiotics, and differences in the nature and severity of infections $[9,10]$.

To investigate this issue further, in rats we developed a model of bilateral pneumonia-septicemia, in which we were able to compare the therapeutic efficacy of individual antibiotics at similar conditions of severity, duration of infection, and host defense. This novel pneumonia-septicemia model was based on a previously established rat model of unilateral pneumonia-septicemia (in which one lung was left uninfected), which was intended for antimicrobial pharmacokinetic and pharmacodynamic studies [11]. Further, in order to mimic the actual clinical situation, the rat infection model is fatal if left untreated, with rat survival (based on rats reaching humane endpoints) as a treatment outcome parameter. In the present study, we established and characterized the lobar pneumonia leading to fatal septicemia, which was caused by either an ESBL-positive K. pneumoniae strain or its isogenic KPC-positive variant. The model was used to investigate the therapeutic efficacy of tigecycline as monotherapy as compared to meropenem monotherapy, a potent carbapenem antibiotic that serves as the conventional treatment for multidrug-resistant, Gram-negative bacterial infections [12].

\section{Materials and Methods}

\subsection{Bacterial Strains}

K. pneumoniae American Type Culture Collection (ATCC) 43816 ${ }^{\mathrm{TM}}$ (capsular serotype 2) was used as a parent strain to generate the isogenic ESBL-producing variant K. pneumoniae ESBL EMC2003 (referred to in this study as K. pneumoniae ESBL) and the isogenic KPC-producing variant K. pneumoniae KPC EMC2014 (referred to in this study as K. pneumoniae KPC) via bacterial conjugation with an ESBL-producing or KPC-producing clinical isolate and subsequent selection on antibiotic agar plates. The stability of both plasmid-containing strains was assessed through five consecutive passages in Mueller-Hinton II broth (Becton Dickinson BV, Vianen, The Netherlands). The virulence of the bacterial strains was maintained by rat lung passage every 12 months. ATCC Quality Control strains K. pneumoniae ATCC $13883^{\mathrm{TM}}$ (WT), K. pneumoniae ATCC $700603^{\mathrm{TM}}$ (ESBL), and K. pneumoniae ATCC BAA1705 ${ }^{\mathrm{TM}}(\mathrm{KPC})$ were used as reference strains.

\subsection{Genotypic Characterization of Bacterial Strains}

Due to the complex relationship between antibiotic resistance and virulence factors, it is important to report the genotypic data of bacterial strains used in microbiological studies $[13,14]$. Polymerase chain reaction (PCR) assays were used to verify the presence of the following resistance genes: cefotaxime (CTX)-M $\beta$-lactamase groups 1, 2, 8, 9, 25 [15]; temoniera (TEM) $\beta$-lactamase [16]; sulfhydryl reagent variable (SHV) $\beta$-lactamase [17]; oxacillinase (OXA) 1-like $\beta$-lactamase groups 1, 48 [18,19]; KPC [20]; and New Delhi metallo- $\beta$-lactamase 1 (NDM) [21]. Multilocus sequence typing (MLST) was used to 
investigate genetic relatedness. For this, partial DNA sequences of the seven housekeeping genes gapA, infB, mdh, pgi, phoE, rpoB, and tonB were generated and compared using a published high-throughput MLST (HiMLST) strategy [22] that had been adapted for K. pneumoniae isolates [23]. To further assess the genetic relation between the strains, pulsed-field gel electrophoresis (PFGE) was used as previously described [24].

\subsection{Antibiotics and Anesthetics}

The antibiotics used were amikacin hydrate, ceftazidime hydrate, ciprofloxacin hydrochloride monohydrate, colistin sulfate salt, gentamicin sulfate, meropenem trihydrate, norfloxacin, tigecycline, tobramycin sulfate salt, trimethoprim, and sulfamethoxazole (Sigma-Aldrich Chemie BV, Zwijndrecht, the Netherlands). For co-trimoxazole, the ratio of trimethoprim/sulfamethoxazole was 1:19. Meropenem was combined with cilastatin sodium (Bosche Scientific LLC, New Brunswick, NJ, USA) (1:1) when used in vivo to inhibit the function of dehydropeptidase enzyme, which is a known catalyst of meropenem in rats [25].

The anesthetics used were medetomidine hydrochloride (Eurovet Animal Health BV, Bladel, The Netherlands), fentanyl citrate (Hameln Pharma Plus GmbH, Hameln, Germany), and midazolam hydrochloride (Actavis Group PTC ehf, Hafnarfjörður, Iceland), which were administered together intraperitoneally at $0.5 \mathrm{mg} / \mathrm{kg}, 50 \mu \mathrm{g} / \mathrm{kg}$, and $5 \mathrm{mg} / \mathrm{kg}$, respectively. Antagonists were atipamezole hydrochloride (Vetoquinol BV's, Hertogenbosch, the Netherlands), naloxone hydrochloride dihydrate (Hameln Pharma Plus GmbH), and flumazenil (Fresenius Kabi Nederland BV, Zeist, The Netherlands), which were administered together intraperitoneally at $1.5 \mathrm{mg} / \mathrm{kg}, 0.7 \mathrm{mg} / \mathrm{kg}$, and $0.3 \mathrm{mg} / \mathrm{kg}$, respectively.

\subsection{Antimicrobial Susceptibility of K. pneumoniae Strains}

The antimicrobial susceptibility of bacterial strains was assessed by determination of the minimum inhibitory concentration (MIC) using the broth microdilution method following EUCAST guidelines [26], which represents the lowest antibiotic concentration needed to inhibit bacterial growth under standardized and predefined laboratory conditions. Phenotypic characterization of bacterial strains was based on antimicrobial susceptibility as determined using the VITEK ${ }^{\circledR} 2$ system and AST-N344 Gram-Negative Susceptibility Cards (bioMérieux Benelux BV, Zaltbommel, The Netherlands).

\subsection{Concentration- and Time-Dependent Bactericidal Activity of Antibiotics In Vitro}

The bacterial killing capacity of meropenem and tigecycline was investigated using the time-kill kinetics (TKK) assay, as previously described [27]. Two-fold increasing antibiotic concentrations were used representing 1/16-fold up to 32-fold the epidemiological cutoff value (ECOFF) values of the two antibiotics, as reported by EUCAST [28]. The ECOFF of K. pneumoniae for meropenem is $0.125 \mathrm{mg} / \mathrm{L}$ and for tigecycline was $1 \mathrm{mg} / \mathrm{L}$, but has recently been increased to $2 \mathrm{mg} / \mathrm{L}$. Samples were centrifuged at $12,500 \times g$ for $5 \mathrm{~min}$ to avoid drug carry-over, serially 10-fold diluted, and subcultured on Mueller Hinton II agar plates (Becton Dickinson BV, Vianen, The Netherlands) for colony-forming unit (CFU) counts after $24 \mathrm{~h}$ at $37^{\circ} \mathrm{C}$. At $24 \mathrm{~h}$, changes in antibiotic susceptibility were determined via MIC assay using subsamples of $1 \mathrm{~mL}$ to prepare bacterial inocula.

\subsection{Animals}

Specified pathogen-free (SPF) male strain RP-AEur-RijHsd albino rats bred at the Laboratory Animals Center of Erasmus University Medical Center Rotterdam (Erasmus MC) were used. Rats (age, 10-18 weeks; body weight, 250-350 g) were housed individually in ventilated cages and were given food and water ad libitum. Rats were randomly allocated to experimental groups once they reached the appropriate age and body weight. Group sizes were based on estimates of the hazard ratio. Euthanasia was applied by $\mathrm{CO}_{2}$ exposure when humane endpoints were reached or at termination of experiments. 


\subsection{Ethics}

Animals were maintained and handled in accordance with the Guidelines for Accommodation and Care of Animals (European Convention for the Protection of Vertebrate Animals Used for Experimental and Other Scientific Purposes). All animal procedures were performed in accordance with the Dutch Animal Experimentation Act (BWBR0003081), which meets the requirements of the European Union Animal Directive (2010/63/EU). Experimental procedures were approved by the Institutional Animal Care and Use Committee of the Erasmus MC. The current study was designed to abide by the "three Rs" principles of animal research (replace, reduce, refine) wherever possible [29] and was written to conform to the animal research: reporting of in vivo experiments (ARRIVE) guidelines for reporting animal research [30].

\subsection{Rat Model of Pneumonia-Septicemia}

Acute bilateral pneumonia-septicemia in rats (referred to in this study as ESBL pneumonia-septicemia or KPC pneumonia-septicemia) was established in groups of 11 rats using suspensions of washed bacteria in the logarithmic phase of growth. After intubation and cannulation of the trachea under anesthesia, rats were held in a vertical position and the lungs were inoculated with $60 \mu \mathrm{L}$ PBS containing the respective absolute lethal dose (LD $\left.{ }^{100}\right)$ inocula: $2 \times 10^{6} \mathrm{~K}$. pneumoniae ESBL or $6 \times 10^{7}$ K. pneumoniae KPC. An implantable programmable temperature transponder (IPTT)-300 (Plexx BV, Elst, The Netherlands) was implanted subcutaneously. Infected rats were monitored 12-hourly for 11 days to assess the disease progression and pre-defined humane endpoints by changes in body temperature and body weight, as well as by external symptoms of disease, including ungroomed appearance, pallor, nose bleeding, lack of reactivity, inactivity, instability, or abnormal breathing of rats. Rat survival was based on rats reaching humane endpoints, at which point euthanasia was applied by $\mathrm{CO}_{2}$ exposure. After dissection, bacteria isolated from lungs and blood were identified by matrix-assisted laser desorption/ionization time-of-flight (MALDI-TOF) mass spectrometry (Bruker Daltonics, Bremen, Germany) to rule out co-infection, a pre-established exclusion criterium.

\subsection{Characterization of Pneumonia-Septicemia Model}

The early phase of infection was characterized at $24 \mathrm{~h}$ and $48 \mathrm{~h}$ after initiation of infection by viable counts of K. pneumoniae in lungs and blood taken from 6 rats per time point. Blood obtained by cardiac puncture was collected from euthanized rats in lithium heparin tubes (Sarstedt BV, Etten-Leur, The Netherlands). The five lung lobes were collected separately in $2 \mathrm{~mL}$ PBS each and homogenized using

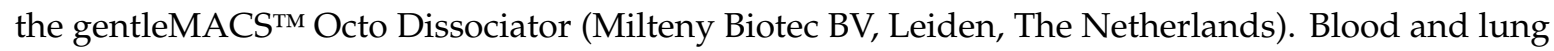
homogenates, either undiluted or in 10-fold dilutions, were subcultured on Mueller-Hinton II agar plates (Sigma-Aldrich Chemie BV, Zwijndrecht, The Netherlands) for CFU counts after $24 \mathrm{~h}$ at $37^{\circ} \mathrm{C}$. In blood plasma samples, the alanine aminotransferase (ALAT) and aspartate aminotransferase (ASAT) levels were assessed for hepatic function, and the creatinine and blood urea nitrogen (BUN) levels were assessed for renal function. Histopathological examination of the infected lungs at $24 \mathrm{~h}$ after infection was performed in 2 rats with ESBL pneumonia-septicemia and 2 rats with KPC pneumonia-septicemia. In sacrificed rats, in situ lungs were fixated with $10 \%$ formalin under constant pressure to re-expand the lungs. Segments of the left lung were dehydrated in ethanol and toluol, and finally embedded in paraffin. Paraffin-embedded tissues were cut into $4-\mu \mathrm{m}$ sections, from which one in every 15 cuts was used for hematoxylin-eosin (HE) staining and one for Gram staining.

\subsection{Antimicrobial Treatment of Pneumonia-Septicemia}

The therapeutic response to meropenem was determined in rats with ESBL pneumonia-septicemia and rats with KPC pneumonia-septicemia. The response to tigecycline was only investigated in rats with KPC pneumonia-septicemia, as this had already been investigated in a previous unilateral pneumonia-septicemia rat model caused by the identical K. pneumoniae ESBL strain [11]. Treatment 
groups consisted of 11 rats. Antibiotics were always administered intraperitoneally at a volume of $2.5 \mathrm{~mL} / \mathrm{kg}$ 12-hourly for 10 days, starting at $24 \mathrm{~h}$ after initiation of infection. Meropenem in doses ranging from 6.25 to $25 \mathrm{mg} / \mathrm{kg} /$ day were administered by 2-fold increases until a minimum effective dose (MED) of meropenem was reached, at which all rats survived. Tigecycline was administered at 25 $\mathrm{mg} / \mathrm{kg} /$ day (i.e., the MED necessary for survival of all rats with ESBL pneumonia-septicemia from a previous study) [11]. Disease progression was monitored 12-hourly. Rats reaching humane endpoints were euthanized and dissected to rule out co-infection.

\subsection{Pharmacokinetics of Meropenem}

Meropenem plasma concentrations were determined in 3 rats with ESBL pneumonia-septicemia. Rats received 3 doses of $25 \mathrm{mg} / \mathrm{kg} /$ day meropenem 12-hourly, starting at $24 \mathrm{~h}$ after initiation of infection. Blood obtained by tail vein puncture was collected in ethylenediaminetetraacetic acid (EDTA) tubes (Sigma-Aldrich Chemie BV, Zwijndrecht, The Netherlands). Meropenem concentrations were determined by high-performance liquid chromatography-mass spectrometry (HPLC-MS) [31]. The lower limit of quantification of meropenem was $0.20 \mathrm{mg} / \mathrm{L}$. The calibration line was linear from 0.20 to $40.0 \mathrm{mg} / \mathrm{L}$, with a determination coefficient of at least 0.995 . Rat samples were prepared together with calibration standards and quality control samples at three levels. The values of the volume of distribution $(V)$, the clearance $(C L)$, and the concentration half-life time $\left(t_{1 / 2}\right)$ of the meropenem elimination process were calculated using a PKSolver 2.0 one-compartment model of extravascular administration with time delay to account for absorption [32]. The $\mathrm{V}$ and CL were presented as a fraction of the absorbed dose (bioavailability, F). The protein binding of meropenem in rats has been reported as $22.4 \%$ [33]. As only the unbound fraction of the drug is responsible for its antimicrobial effect, the values of (1) the cumulative percentage of a 12-h period that the unbound fraction of drug exceeded the MIC ( $f$ T > MIC) and (2) the highest unbound meropenem concentration reached in blood plasma $\left(f C_{\max }\right)$, were calculated based on unbound meropenem concentrations.

\subsection{Statistical Analysis}

Kaplan-Meier rat survival curves were generated, and statistical differences in rat survival rates were calculated using the log rank test using Prism 5.01 (Graphpad Inc., San Diego, CA, USA).

\section{Results}

\subsection{Bacterial Strains}

The results from HiMLST (Supplementary Table S1) and PFGE assays confirmed the isogenicity of the K. pneumoniae ESBL and K. pneumoniae KPC strains. ESBL and KPC resistance genes were detected via PCR, as expected in the respective strains (Supplementary Table S1).

\subsection{Antimicrobial Susceptibility of K. pneumoniae Strains}

The antimicrobial susceptibility of K. pneumoniae ESBL and K. pneumoniae KPC for clinically relevant antibiotics was assessed by MIC determination and compared with the MIC values of 3 ATCC Quality Control reference strains. The K. pneumoniae ESBL strain was resistant to ceftazidime and tobramycin, and susceptible to meropenem based on MIC values (Table 1). The isogenic K. pneumoniae KPC strain was resistant to ceftazidime, tobramycin, and meropenem. According to the EUCAST 2020 guidelines, both $K$. pneumoniae isolates are resistant to tigecycline, as are all the reference strains used in this study [26]. However, both K. pneumoniae isolates still fell within the antimicrobial wild-type distribution of K. pneumoniae based on the ECOFF value of tigecycline for K. pneumoniae (2 mg/L), and can be considered representative of the tigecycline susceptibility of wild-type K. pneumoniae populations-albeit on the high end of the wild-type distribution [28]. 
Table 1. Minimum inhibitory concentration (MIC) values of clinically relevant antibiotics for $K$. pneumoniae strains.

\begin{tabular}{|c|c|c|c|c|c|c|c|}
\hline \multicolumn{2}{|c|}{ Strain } & $\begin{array}{c}\text { ATCC } \\
43816\end{array}$ & $\begin{array}{l}\text { EMC } \\
2003\end{array}$ & $\begin{array}{l}\text { EMC } \\
2014\end{array}$ & $\begin{array}{l}\text { ATCC } \\
13883\end{array}$ & $\begin{array}{l}\text { ATCC } \\
700603\end{array}$ & $\begin{array}{c}\text { ATCC } \\
\text { BAA1705 }\end{array}$ \\
\hline \multicolumn{2}{|c|}{ Phenotype } & WT Parent & ESBL & KPC & WT & ESBL & KPC \\
\hline \multirow{9}{*}{$\begin{array}{c}\mathrm{MIC} \\
(\mathrm{mg} / \mathrm{L})\end{array}$} & CAZ & $0.5^{\mathrm{S}}$ & $256^{\mathrm{R}}$ & $256^{R}$ & $0.5^{\mathrm{S}}$ & $64^{\mathrm{R}}$ & $128^{\mathrm{R}}$ \\
\hline & MEM & $0.063^{\mathrm{S}}$ & $0.063^{\mathrm{S}}$ & $16^{\mathrm{R}}$ & $0.063^{\mathrm{S}}$ & $0.063^{\mathrm{S}}$ & $32^{R}$ \\
\hline & AMK & $2^{S}$ & $2^{S}$ & $2^{S}$ & $1^{S}$ & $1^{S}$ & $32^{R}$ \\
\hline & ТОВ & $0.5^{\mathrm{S}}$ & $\geq 128^{R}$ & $\geq 128^{R}$ & $0.5^{\mathrm{S}}$ & $8^{R}$ & $32^{R}$ \\
\hline & CIP & $0.031^{\mathrm{S}}$ & $0.125^{\mathrm{S}}$ & $0.063^{\mathrm{S}}$ & $0.125^{\mathrm{S}}$ & $0.5^{\mathrm{I}}$ & $\geq 64^{\mathrm{R}}$ \\
\hline & NOR & $0.125^{\mathrm{S}}$ & $0.25^{\mathrm{S}}$ & $0.25^{\mathrm{S}}$ & $0.25^{\mathrm{S}}$ & $2^{R}$ & $512^{R}$ \\
\hline & SXT & $0.5^{\mathrm{S}}$ & $1^{S}$ & $2^{S}$ & $0.5^{\mathrm{S}}$ & $4^{\mathrm{I}}$ & $\geq 128^{\mathrm{R}}$ \\
\hline & CST & $0.5^{\mathrm{S}}$ & $1^{S}$ & $0.5^{\mathrm{S}}$ & $2^{S}$ & $1^{S}$ & $0.5^{\mathrm{S}}$ \\
\hline & TGC & $1^{\mathrm{R}}$ & $1^{\mathrm{R}}$ & $2^{R}$ & $1^{\mathrm{R}}$ & $16^{\mathrm{R}}$ & $4^{\mathrm{R}}$ \\
\hline
\end{tabular}

MIC assays were performed in triplicate; median values are displayed. MIC values were interpreted as susceptible $\left({ }^{S}\right)$, intermediate $\left({ }^{\mathrm{P}}\right)$, or resistant $\left({ }^{\mathrm{R}}\right)$ according to EUCAST 2020 guidelines. ATCC, American Type Culture Collection; EMC, Erasmus University Medical Center Rotterdam; CAZ, ceftazidime; MEM, meropenem; AMK, amikacin; TOB, tobramycin; CIP, ciprofloxacin; NOR, norfloxacin; SXT, trimethoprim/sulfamethoxazole expressed as the trimethoprim concentration; CST, colistin; TGC, tigecycline; WT, wildtype; ESBL, extended-spectrum $\beta$-lactamase; $\mathrm{KPC}$, Klebsiella pneumoniae carbapenemase.

VITEK ${ }^{\circledR} 2$ data (Supplementary Table S2) showed that K. pneumoniae ESBL and K. pneumoniae KPC were both resistant to a wide range of $\beta$-lactam antibiotics and aminoglycoside antibiotics.

\subsection{Concentration- and Time-Dependent Bactericidal Activity of Antibiotics In Vitro}

The in vitro killing capacity of meropenem and tigecycline against K. pneumoniae ESBL or K. pneumoniae KPC over $24 \mathrm{~h}$ was determined using TKK assays. In the absence of antibiotics, the bacterial populations rapidly increased within $24 \mathrm{~h}$ of incubation (Figure 1). Meropenem showed time-dependent killing against K. pneumoniae ESBL. A concentration of $\geq 0.125 \mathrm{mg} / \mathrm{L}$ meropenem resulted in a 100-fold reduction in bacterial numbers after $2 \mathrm{~h}$ and complete bacterial elimination after $24 \mathrm{~h}$. With $0.03 \mathrm{mg} / \mathrm{L}$ meropenem, bacteria were initially killed, although after $24 \mathrm{~h}$, bacterial re-growth occurred up to the level of non-exposed bacterial growth after $24 \mathrm{~h}$. However, this finding was not associated with changes in susceptibility to meropenem. Concentrations of $\leq 0.015 \mathrm{mg} / \mathrm{L}$ meropenem had no effect on in vitro bacterial growth. For K. pneumoniae KPC, initial killing by meropenem was observed at concentrations $\geq 0.5 \mathrm{mg} / \mathrm{L}$ during the first $2 \mathrm{~h}$ exposure, but bacterial re-growth was observed at all concentrations up to the level of non-exposed bacteria after $24 \mathrm{~h}$.

The mode of action of tigecycline was observed to be bacteriostatic and the antibiotic was equally effective against K. pneumoniae ESBL and K. pneumoniae KPC, indicating that the 2-fold difference in MIC values to tigecycline for the two strains represents essential agreement in susceptibility to this antibiotic. Inhibition of bacterial growth after $24 \mathrm{~h}$ of exposure was only observed above $2 \mathrm{mg} / \mathrm{L}$ tigecycline. Concentrations below $2 \mathrm{mg} / \mathrm{L}$ resulted in growth inhibition during $4 \mathrm{~h}$ of exposure, but bacterial re-growth occurred after $24 \mathrm{~h}$, which was never associated with changes in bacterial susceptibility to tigecycline. Concentrations $\leq 0.25 \mathrm{mg} / \mathrm{L}$ had no effect. 
K. pneumoniae ESBL

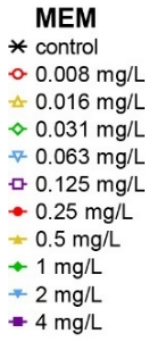

TGC

* control

$0.063 \mathrm{mg} / \mathrm{L}$

$\star 0.125 \mathrm{mg} / \mathrm{L}$

$\diamond 0.25 \mathrm{mg} / \mathrm{L}$

$\forall 0.5 \mathrm{mg} / \mathrm{L}$

ㅁ. $1 \mathrm{mg} / \mathrm{L}$

$-2 \mathrm{mg} / \mathrm{L}$

$+4 \mathrm{mg} / \mathrm{L}$

$+8 \mathrm{mg} / \mathrm{L}$

$* 16 \mathrm{mg} / \mathrm{L}$

- $32 \mathrm{mg} / \mathrm{L}$

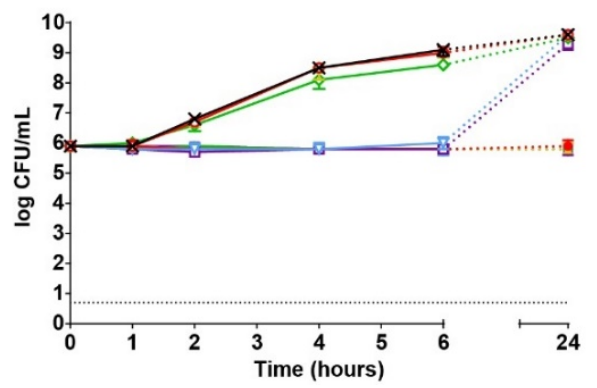

K. pneumoniae KPC
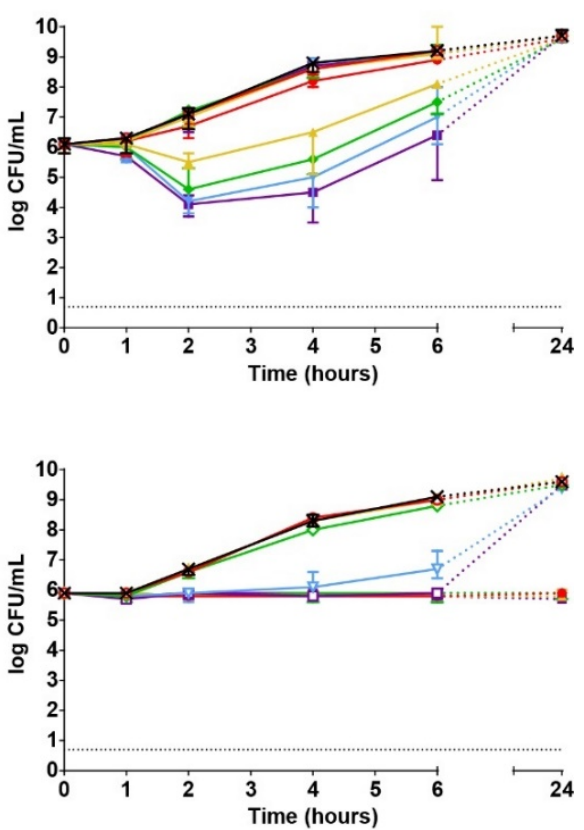

Figure 1. Concentration- and time-dependent bactericidal activity of meropenem (MEM) and tigecycline (TGC) against K. pneumoniae strains. Bacterial cultures of K. pneumoniae ESBL or K. pneumoniae KPC were exposed to two-fold increasing concentrations of antibiotic for $24 \mathrm{~h}$. Shown are the median \pm range of in triplicate experiments. The dashed grey line indicates the lower limit of quantification of $\log 0.7$.

\subsection{Characterization of Pneumonia-Septicemia Model}

Rats were inoculated with K. pneumoniae ESBL or K. pneumoniae KPC and developed acute bilateral pneumonia with septicemia. Bacterial numbers increased rapidly in all lung lobes, with the relatively large lobes containing the most bacteria (Figure 2). As a consequence of a higher inoculum used to induce KPC pneumonia-septicemia, higher counts of K. pneumoniae were found at $24 \mathrm{~h}$ in the lungs of rats with KPC pneumonia-septicemia compared to rats with ESBL pneumonia-septicemia. By $48 \mathrm{~h}$, differences in K. pneumoniae counts in the lungs in both models were minor. After $24 \mathrm{~h}$, bacteremia was present in 4/6 (66\%) rats with ESBL pneumonia-septicemia and in 4/6 (66\%) rats with KPC pneumonia-septicemia. Changes in liver and kidney function in terms of ALAT, ASAT, creatinine, and BUN were not found. Histopathological examination of the infected lungs at $24 \mathrm{~h}$ after initiation of infection revealed distinctive alveolar pathology, as shown for KPC pneumonia-septicemia (Figure A1 in Appendix A). Similar histopathological characteristics were observed in rats with ESBL pneumonia-septicemia.

The disease progression over time in terms of rat survival rate (Figure 3A) was similar for either infecting K. pneumoniae strain ( $p=0.4662)$. In both cases, the body temperatures (Figure 3B) initially showed some fluctuation, but decreased over time to below the lower limit $\left(36.1^{\circ} \mathrm{C}\right)$ of normal values. Rat body weight decreased over time (Figure 3C). A control experiment revealed that the technique of intubation and inoculation itself did not influence body temperature or body weight. 
ESBL pneumonia/septicemia

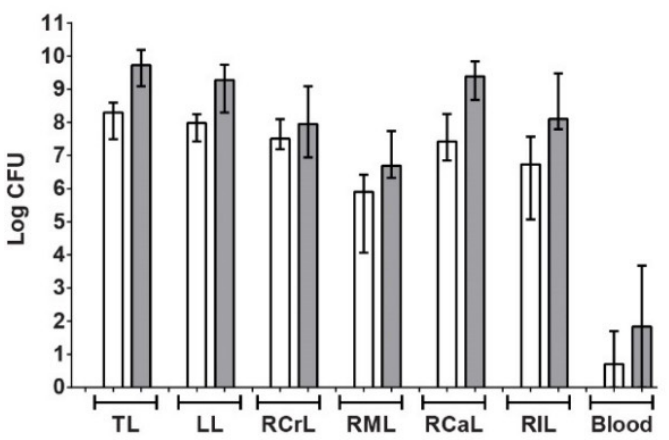

KPC pneumonia/septicemia

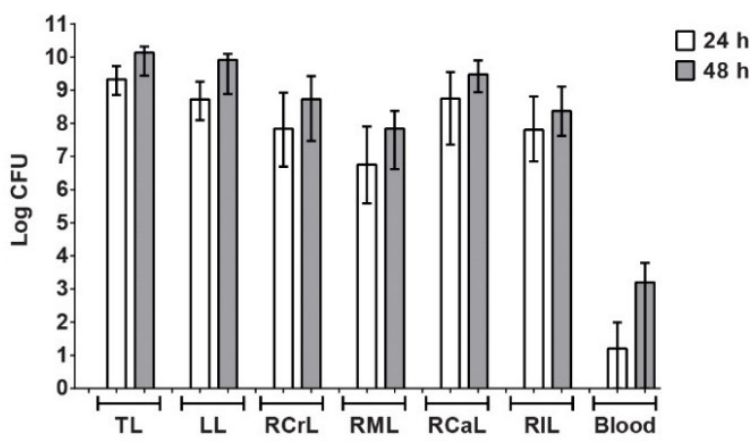

Figure 2. Bacterial load of K. pneumoniae in lungs and blood of rats with K. pneumoniae pneumonia-septicemia in the early phase of infection. Bacterial load of K. pneumoniae was determined for total lungs and individual lung lobes and blood (per $\mathrm{mL}$ ) of rats with K. pneumoniae ESBL pneumonia-septicemia and rats with K. pneumoniae KPC pneumonia-septicemia at $24 \mathrm{~h}$ and $48 \mathrm{~h}$ after initiation of infection. TL, total lungs; LL, left lobe; RCrL, right cranial lobe; RML, right middle lobe; $\mathrm{RCaL}$, right caudal lobe; RIL, right intermediate lobules. Groups of 6 rats per time point. Bacterial load is expressed as log CFU (median \pm range).
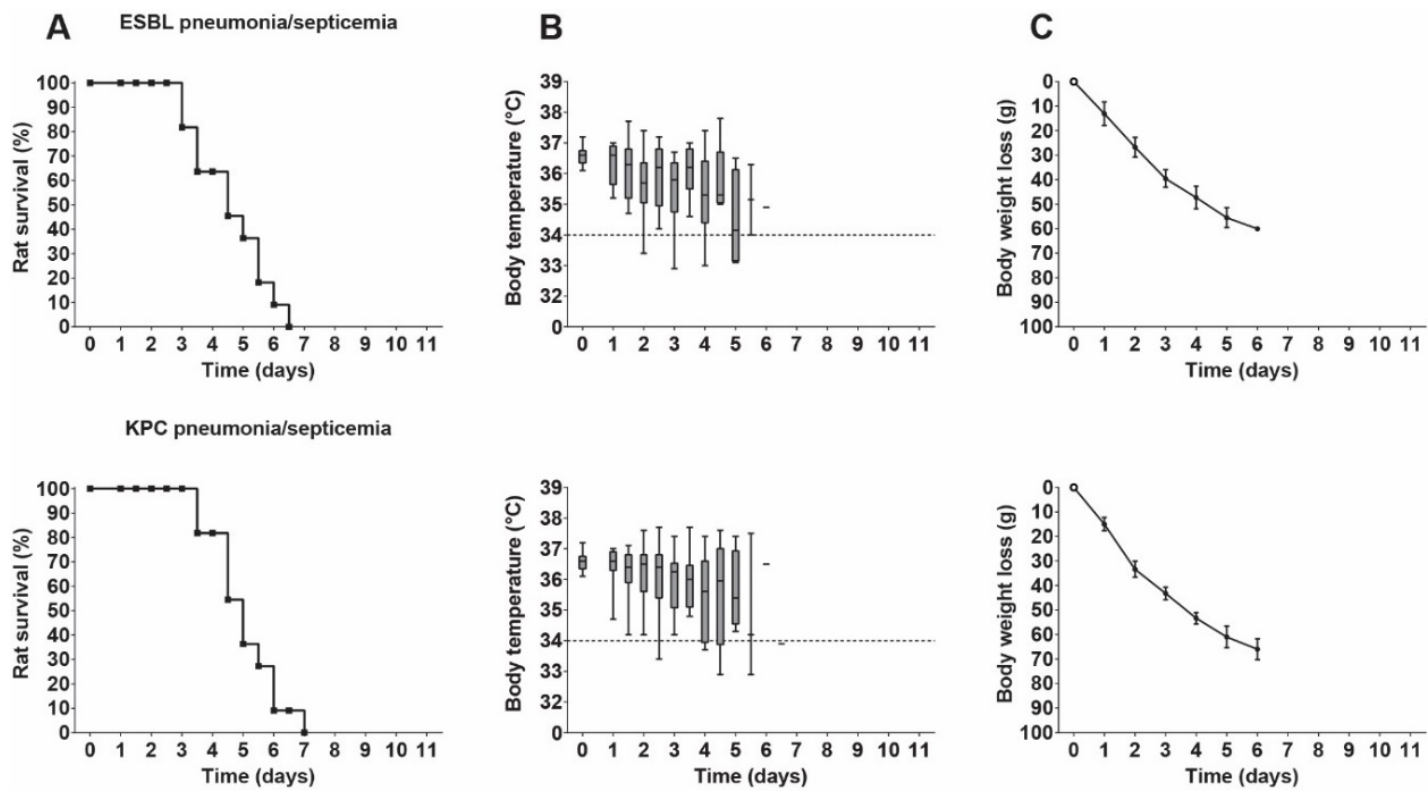

Figure 3. Disease progression in rats with K. pneumoniae pneumonia-septicemia. Groups of 11 rats were used for each experiment. (A) Rat survival (Kaplan-Meier curves) of rats reaching humane endpoints. (B) Box plots of pooled body temperatures showing the range of the data; the dashed line at $34{ }^{\circ} \mathrm{C}$ represents the humane endpoint. (C) Body weight loss from the onset of the infection (mean $\pm \mathrm{SD}$ ).

\subsection{Therapeutic Efficacy of Meropenem in Rats with ESBL Pneumonia-Septicemia}

Treatment was started at $24 \mathrm{~h}$ after infection, when bacterial numbers in the lung had increased 100 -fold and most rats had developed early bacteremia. Increasing doses of meropenem were investigated, ranging from 6.25 to $25 \mathrm{mg} / \mathrm{kg} /$ day administered 12-hourly until a MED of meropenem was reached, at which all rats survived. Meropenem showed a dose-dependent therapeutic activity and effected survival of all rats at $25 \mathrm{mg} / \mathrm{kg} / \mathrm{day}$ - the MED (Figure 4). Rat body temperatures initially showed some fluctuation but stabilized around normal values after 3 days, from which time onward normal circadian rhythm was shown. Body weight values initially decreased but remained stable after 3 days. The lungs of the surviving rats sacrificed at termination of the experiment were sterile. 

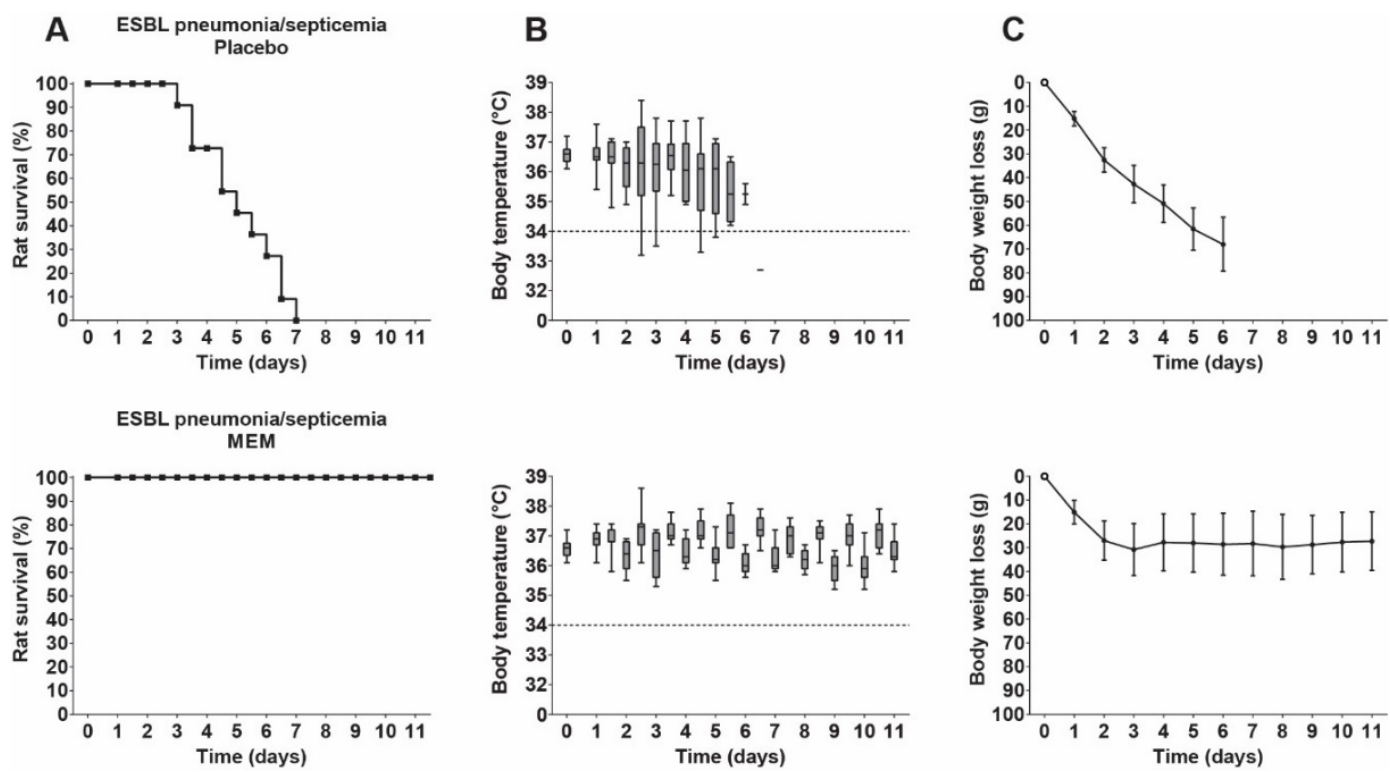

Figure 4. Therapeutic efficacy of meropenem (MEM) in rats with ESBL pneumonia-septicemia. Groups of 11 rats were treated 12-hourly for 10 days with placebo (physiological saline) or $25 \mathrm{mg} / \mathrm{kg} / \mathrm{day}$ meropenem, starting at $24 \mathrm{~h}$ after initiation of infection. (A) Rat survival (Kaplan-Meier curves) of rats reaching humane endpoints. (B) Box plots of pooled body temperatures showing the range of the data; the dashed line at $34{ }^{\circ} \mathrm{C}$ represents the humane endpoint. (C) Body weight loss (mean $\pm \mathrm{SD}$ ).

\subsection{Pharmacokinetics of Meropenem in Rats with ESBL Pneumonia-Septicemia}

Meropenem plasma concentrations were determined to investigate the steady-state pharmacokinetic profile of meropenem at MED in rats with ESBL pneumonia-septicemia. The plasma concentration-time curve indicated a one-compartment deposition (Figure 5). The corresponding estimated pharmacokinetic parameters are displayed in Table 2. The $f \mathrm{~T}>\mathrm{MIC}$ for K. pneumoniae ESBL was $5.18 \mathrm{~h}$, which was $43.17 \%$ of the twice-daily dosing interval. For K. pneumoniae KPC, the $f C_{\max }$ $(13.37 \mathrm{mg} / \mathrm{L})$ did not reach the respective meropenem MIC $(16 \mathrm{mg} / \mathrm{L})$, resulting in a $f \mathrm{~T}>$ MIC of $0 \mathrm{~h}$.

\section{ESBL pneumonia/septicemia}

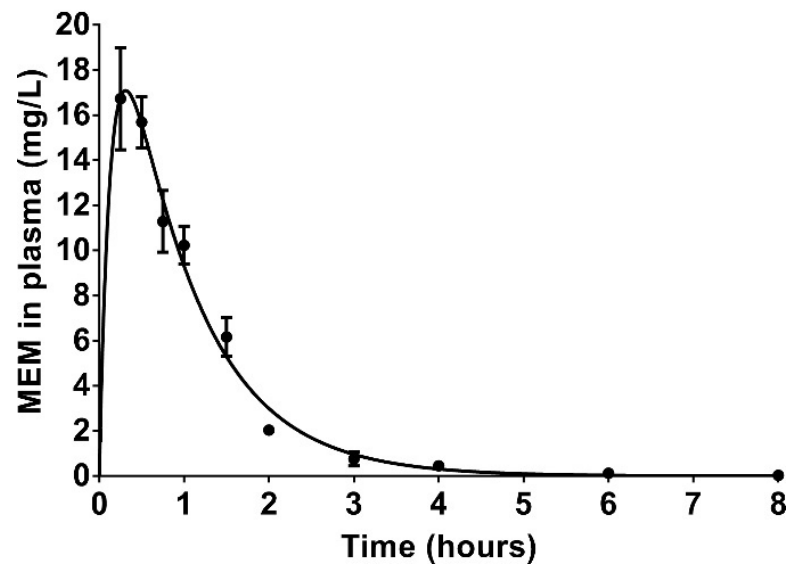

Figure 5. Plasma concentrations of total (bound and unbound) meropenem (MEM) in rats with ESBL pneumonia-septicemia. Rats were treated 12-hourly with 3 consecutive doses of $25 \mathrm{mg} / \mathrm{kg} / \mathrm{day}$ meropenem, starting at $24 \mathrm{~h}$ after initiation of infection. The concentration-time curve predicted by a one-compartment model of extravascular administration was imposed over the observed concentrations at each time point in 3 rats (mean \pm SEM). 
Table 2. Pharmacokinetic parameters of meropenem in rats with ESBL pneumonia-septicemia.

\begin{tabular}{|c|c|c|c|c|c|c|c|c|}
\hline \multirow{3}{*}{$\begin{array}{c}\text { Pharmacokinetic } \\
\text { Parameter }\end{array}$} & \multirow{3}{*}{$\begin{array}{l}\text { V/F } \\
\mathrm{L} / \mathrm{kg}\end{array}$} & \multirow{3}{*}{$\begin{array}{c}\mathrm{CL} / \mathrm{F} \\
\mathrm{L} / \mathrm{kg} / \mathrm{h}\end{array}$} & \multirow{3}{*}{$\begin{array}{c}\mathbf{t}_{1 / 2} \\
h\end{array}$} & \multirow{3}{*}{$\begin{array}{c}f \mathrm{C} \max \\
\mathrm{mg} / \mathrm{L}\end{array}$} & \multicolumn{4}{|c|}{$f \mathrm{~T}>\mathrm{MIC}$} \\
\hline & & & & & \multicolumn{2}{|c|}{$0.063 \mathrm{mg} / \mathrm{L}$} & \multicolumn{2}{|c|}{$16 \mathrm{mg} / \mathrm{L}$} \\
\hline & & & & & h & $\%$ & $\mathrm{~h}$ & $\%$ \\
\hline Estimate & 1.03 & 1.17 & 0.61 & 13.37 & 5.18 & 43.17 & 0.00 & 0.00 \\
\hline SEM & 0.07 & 0.06 & 0.03 & 1.43 & 0.24 & 2.00 & 0.00 & 0.00 \\
\hline
\end{tabular}

Plasma concentrations of meropenem in rats with ESBL pneumonia-septicemia treated 12-hourly with 3 consecutive doses of $25 \mathrm{mg} / \mathrm{kg}$ meropenem, starting at $24 \mathrm{~h}$ after initiation of infection. The $f \mathrm{~T}>\mathrm{MIC}$ was calculated based on unbound meropenem concentrations using the MIC of $K$. pneumoniae ESBL $(0.063 \mathrm{mg} / \mathrm{L})$ and the MIC of $K$. pneumoniae $\mathrm{KPC}(16 \mathrm{mg} / \mathrm{L})$ and is shown in hours $(\mathrm{h})$ as well as percentage of the 12 -h dosing interval (\%). V, volume of distribution; $\mathrm{F}$, bioavailability; $\mathrm{CL}$, clearance; $\mathrm{t}_{1 / 2}$, elimination half-life time; $f \mathrm{Cmax}$, highest unbound meropenem concentration reached in blood plasma; $f \mathrm{~T}>\mathrm{MIC}$, cumulative percentage of a 12-h period that the unbound fraction of drug exceeds the MIC.

\subsection{Therapeutic Efficacy of Meropenem and Tigecycline in Rats with KPC Pneumonia-Septicemia}

Rats with KPC pneumonia-septicemia were treated with $25 \mathrm{mg} / \mathrm{kg} /$ day meropenem 12-hourly for 10 days, which correlates to a $f \mathrm{~T}>\mathrm{MIC}$ of $0 \mathrm{~h}$. This treatment resulted in survival of only 1/12 rats with KPC pneumonia-septicemia (Figure 6), which was not significantly different compared to the placebo-treated rats $(p=0.5728)$. The failure of meropenem treatment was also reflected in the body temperatures and the body weight values.
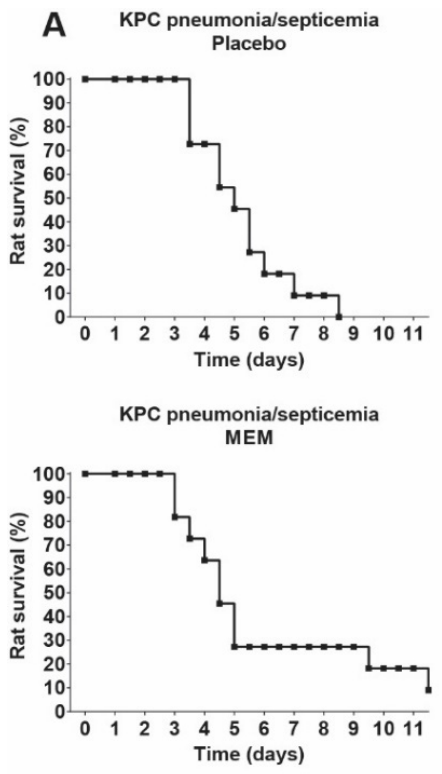

KPC pneumonia/septicemia

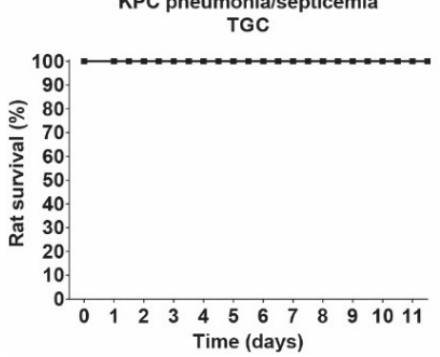

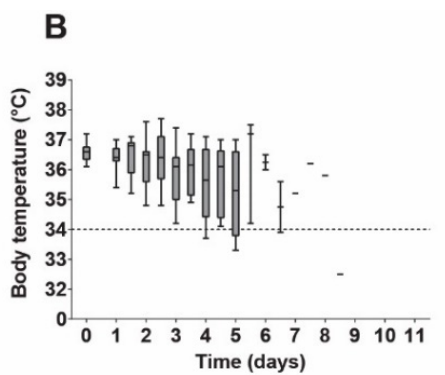
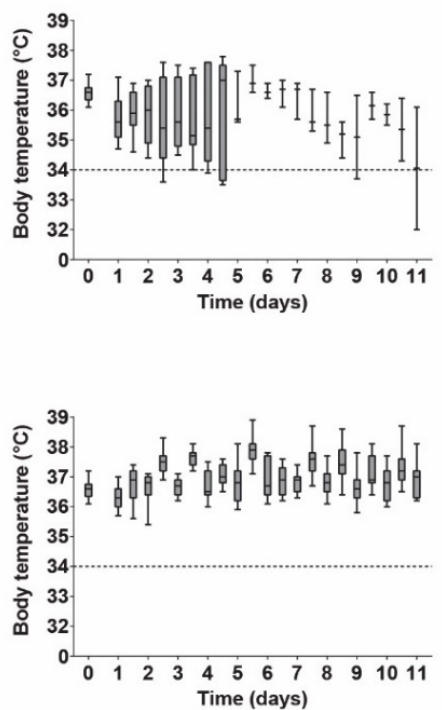
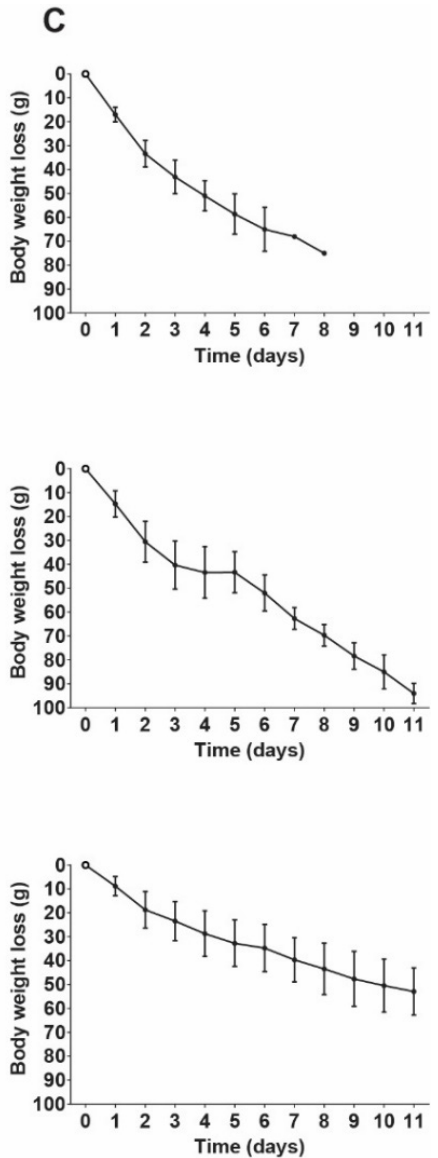

Figure 6. Therapeutic efficacy of meropenem (MEM) or tigecycline (TGC) in rats with KPC pneumonia-septicemia. Groups of 11 rats were treated 12-hourly for 10 days with placebo (physiological saline), $25 \mathrm{mg} / \mathrm{kg} /$ day meropenem, or $25 \mathrm{mg} / \mathrm{kg} /$ day tigecycline, starting at $24 \mathrm{~h}$ after initiation of infection. (A) Rat survival (Kaplan-Meier curves) of rats reaching humane endpoints. (B) Box plots of pooled body temperatures showing the range of the data; the dashed line at $34{ }^{\circ} \mathrm{C}$ represents the humane endpoint. (C) Body weight loss (mean $\pm \mathrm{SD}$ ). 
Next, the therapeutic response to tigecycline treatment of $25 \mathrm{mg} / \mathrm{kg} / \mathrm{day}$ 12-hourly for 10 days was investigated in rats with KPC pneumonia-septicemia. This dosage was the MED of tigecycline found in a previous unilateral pneumonia-septicemia rat model caused by an identical K. pneumoniae ESBL strain [11]. The $25 \mathrm{mg} / \mathrm{kg} /$ day tigecycline dosage resulted in survival of all rats with bilateral KPC pneumonia-septicemia. Body temperatures remained stable, but body weights decreased slowly over time (Figure 6). Low bacterial numbers were present in the lungs of the surviving rats, with a median of $2.6 \times 10^{3} \mathrm{~K}$. pneumoniae and an upper limit of $1.9 \times 10^{4} \mathrm{~K}$. pneumoniae. None of the isolated bacteria showed a change in susceptibility to tigecycline.

\section{Discussion}

Antimicrobial resistance continues to spread worldwide and is often encountered in clinically relevant organisms such as K. pneumoniae. This bacterial species is becoming increasingly resistant to currently available antibiotics [3,34], with many isolates only susceptible to a limited number of "last resort" antibiotics, such as colistin and tigecycline. However, much debate still exists on the clinical efficacy of tigecycline in relation to the dose administered. Freire et al. in 2010 showed a lower therapeutic response for tigecycline than imipenem (using a dosing regimen of $100 \mathrm{mg}$ initially followed by $50 \mathrm{mg}$ every $12 \mathrm{~h}$ in a group of ventilated patients), a study often referenced as showing the limited efficacy of tigecycline in this situation [35]. Additionally, the administration of tigecycline treatment has been associated with an increased death rate [5], and a number of case reports have indicated serious complications in patients as a consequence of tigecycline treatment [36-40]. On the other hand, a meta-analysis by Falagas et al. in 2014 concluded that high-dose tigecycline regimens may be effective for the treatment of severe bacterial infections [9], and a meta-analysis by Gong et al. concluded that high-dose tigecycline regimens did not elevate the risk of toxic side effects [41]. Further, pharmacokinetic and pharmacodynamic studies have indicated that higher dosages of tigecycline can be administered to humans, resulting in improved therapeutic efficacy $[6,42,43]$. This has been corroborated by more recent studies, which have shown that administration of high-dose tigecycline regimens are tolerated and result in improved therapeutic efficacy in infected patients compared to conventional tigecycline dosing [43-47]. Cunha et al. reported clinical efficacy using once-daily high-dose tigecycline monotherapy in the treatment of multidrug-resistant Gram-negative bacilli and published recommendations for high-dose regimens [7,42]. These studies are also supported by the in vitro modeling studies of Tsala et al., suggesting that higher doses of tigecycline are required to achieve therapeutic efficacy [48], and by a Monte Carlo simulation analysis of standard and high-dose tigecycline against carbapenemase-producing K. pneumoniae, showing that the cumulative fractional response rate of $>90 \%$ was only achievable with the high-dose tigecycline regimen [49]. Taken together, these studies suggest that current clinical guidelines on the antibiotic prescription of tigecycline may need to be revised upwards in order to reach a clinically effective dose. In this respect, EUCAST has recently published the new Guidance Document on Tigecycline Dosing by the EUCAST, recommending the use of high-dosage tigecycline treatment in seriously ill patients infected with multidrug-resistant bacteria [8].

Complicating this debate is the fact that tigecycline is frequently applied in the treatment of infections caused by multidrug-resistant bacteria as part of combination therapy rather than monotherapy [10]. Based on these limitations and on accompanying discussions relating to the efficacy of tigecycline administration, a study was established into the efficacy of high-dose tigecycline monotherapy using a newly established rat model of fatal acute pneumonia-septicemia caused by ESBLor KPC-positive K. pneumoniae with meropenem as a comparator drug. This model is representative of a particularly severe multidrug-resistant infection in human patients [50-52] and allows for research comparing the therapeutic efficacy of individual antibiotics at similar conditions of severity, duration of infection, and host defense, which is not possible with most comparative clinical efficacy studies on tigecycline treatment $[9,10]$. 
Treatment with tigecycline at $25 \mathrm{mg} / \mathrm{kg} /$ day 12 -hourly for 10 days resulted in $100 \%$ survival of rats with KPC pneumonia-septicemia and normalization of body temperature. In our previous study using the K. pneumoniae ESBL unilateral pneumonia-septicemia model, this tigecycline dosage was the successful MED, generating 100\% survival of rats and normalization of body temperature. In the same study, the efficacy of tigecycline was found to be dose-dependent and was correlated to the ratio of the area under the plasma concentration-time curve (AUC) to the MIC (AUC/MIC). The AUC during a 24-h period ( $\mathrm{AUC}_{0-24 \mathrm{~h}}$ ) for this tigecycline dosage in rats with was similar to the $\mathrm{AUC}_{0-24 \mathrm{~h}}$ of high-dose tigecycline treatments in human patients (a loading dose of $300 \mathrm{mg}$ tigecycline followed by $150 \mathrm{mg}$ tigecycline every $12 \mathrm{~h}$ ) [53]. For pneumonia-septicemia caused by K. pneumoniae ESBL with a tigecycline MIC of $1 \mathrm{mg} / \mathrm{L}$, the AUC/MIC was $34.29 \mathrm{mg} \cdot \mathrm{h} / \mathrm{L}$ at a tigecycline dosage of $25 \mathrm{mg} / \mathrm{kg} / \mathrm{day}$, which was the MED of tigecycline for survival of all rats. As the tigecycline MIC of K. pneumoniae KPC is $2 \mathrm{mg} / \mathrm{L}$, the extrapolated AUC/MIC ratio for KPC pneumonia-septicemia at a tigecycline dosage of $25 \mathrm{mg} / \mathrm{kg} /$ day is calculated to be $17.15 \mathrm{mg} \cdot \mathrm{h} / \mathrm{L}$. Despite this MED having a lower AUC/MIC ratio in rats with bilateral KPC pneumonia-septicemia, the tigecycline treatment at $25 \mathrm{mg} / \mathrm{kg} /$ day 12 -hourly for 10 days remained successful. Unlike the meropenem treatment, this treatment did not result in normalization of body weight, which might be explained by either the persistence of low bacterial numbers in the lungs of the rats at the end of treatment or by potential gastro-intestinal side effects of tigecycline.

Treatment with meropenem in rats with ESBL pneumonia-septicemia showed a clear dose-response relationship. At the MED of $25 \mathrm{mg} / \mathrm{kg} / \mathrm{day}$, meropenem resulted in $100 \%$ rat survival, stabilization of body weight, body temperature returning to the circadian rhythm, and effected bacterial elimination from the lung tissue at the end of treatment. Meropenem concentrations in rat plasma remained above the MIC of K. pneumoniae ESBL for $>5 \mathrm{~h}$, achieving the bactericidal target of carbapenem regimens in human patients, which is a $f \mathrm{~T}>\mathrm{MIC}$ of approximately $40 \%$ of the dosing interval [54]. In terms of total dosage, meropenem at $25 \mathrm{mg} / \mathrm{kg} /$ day 12-hourly for 10 days in rats is similar to the current clinical treatment of ESBL pneumonia-septicemia, although in patients, an 8-hourly meropenem schedule is more common [55].

The MED of meropenem in rats with ESBL pneumonia-septicemia was not successful in rats with KPC pneumonia-septicemia, which is in line with the difference in susceptibility of K. pneumoniae ESBL and K. pneumoniae KPC. This difference in susceptibility resulted in different $f \mathrm{~T}>\mathrm{MIC}$ values for the two strains, with unbound meropenem concentrations in rat plasma remaining above the MIC of $K$. pneumoniae ESBL for $>5 \mathrm{~h}$, whereas the $f C_{\max }(<14 \mathrm{mg} / \mathrm{L})$ did not reach the meropenem MIC of K. pneumoniae $\mathrm{KPC}(16 \mathrm{mg} / \mathrm{L})$, resulting in a $f \mathrm{~T}>\mathrm{MIC}$ of $0 \mathrm{~h}$. The respective therapeutic success or failure of this meropenem dose in both infection models can be explained as a consequence of the time-dependent bactericidal activity of meropenem, which was shown in the in vitro TKK data in the present study, as well as in other in vivo pharmacokinetic and pharmacodynamic studies [56].

The pneumonia-septicemia model established in the present study is representative of a particularly severe human infection with K. pneumoniae bacteria, resulting in rapid mortality when left untreated [50-52]. Further, although the tigecycline MIC of K. pneumoniae ESBL (1 mg/L) and K. pneumoniae KPC (2 mg/L) are considered resistant, these MICs remain within the wild-type distribution of tigecycline MICs for K. pneumoniae [26,28]. In view of these factors, the successful treatment of this animal model necessitated the use of a high-dose tigecycline regimen, as the AUC of the tigecycline monotherapy MED administered to rats with ESBL pneumonia-septicemia exceeds the AUC of the tigecycline dosage that is conventionally administered to infected patients (50 $\mathrm{mg}$ tigecycline every $12 \mathrm{~h}$ ) [57], demonstrating the effectiveness of high-dosage tigecycline regimens in the treatment of severe multidrug-resistant bacterial infections. The scope of the current research was limited to investigating the efficacy of a high-dosage tigecycline regimen in a model of pneumonia-septicemia caused by two isogenic, multidrug-resistant K. pneumoniae strains. Future research can improve on the generalizability of these results by investigating high-dosage tigecycline regimens in the treatment of infection models caused by other K. pneumoniae strains or different Gram-negative bacterial species. 
Another interesting avenue for further research with the current pneumonia-septicemia model would be the investigation of high-dose meropenem regimens [58] or high-dose meropenem and high-dose tigecycline combination regimens [59].

\section{Conclusions}

The data obtained in the current study provide evidence that high-dosage tigecycline monotherapy is effective in a rat model representative of human pneumonia-septicemia caused by multidrug-resistant K. pneumoniae. Based on the therapeutic tigecycline dose observed in this publication, the limited susceptibility to tigecycline of both strains, and current clinical guidelines, the in vivo data reported in the present study further supports recent literature on the applicability of high-dosage tigecycline as a treatment of "last resort" in patients for severe multidrug-resistant K. pneumoniae infections. The present work involves a clinically relevant animal model for multidrug-resistant K. pneumoniae infections that facilitates the future investigation of antibiotics and novel therapeutic approaches to pneumonia-septicemia.

Supplementary Materials: The following are available online at http://www.mdpi.com/2079-6382/9/3/109/s1: Table S1: Genotypic characterization of K. pneumoniae strains-MLST data and PCR data. Table S2: Phenotypic characterization of K. pneumoniae strains-VITEK ${ }^{\circledR}$ MIC values of clinically relevant antibiotics.

Author Contributions: The authors provided the following individual contributions: conceptualization, H.V.d.W., M.T.T.K., J.P.H., W.H.F.G., and I.A.J.M.B.-W.; methodology, H.V.d.W., M.T.T.K., J.P.H., W.H.F.G., and I.A.J.M.B.-W.; software, H.V.d.W., R.A.W., and S.A.B.; validation, H.V.d.W., M.T.T.K., D.M.C.V.-d.J., R.A.W., and S.A.B.; formal analysis, H.V.d.W., R.A.W., and S.A.B.; investigation, H.V.d.W., M.T.T.K., D.M.C.V.-d.J., and A.V.d.M.; resources, R.A.W., S.A.B., J.P.H., and W.H.F.G.; data curation, H.V.d.W., M.T.T.K., and S.A.B.; writing-original draft preparation, H.V.d.W.; writing—review and editing, M.T.T.K., A.V.d.M., M.V.W., J.P.H., W.H.F.G., and I.A.J.M.B.-W.; visualization, H.V.d.W.; supervision, J.P.H., W.H.F.G., and I.A.J.M.B.-W.; project administration, J.P.H., W.H.F.G., and I.A.J.M.B.-W.; funding acquisition, J.P.H., W.H.F.G., and I.A.J.M.B.-W. All authors have read and agreed to the published version of the manuscript.

Funding: This research was funded by the European Union's Seventh Program for Research, Technological Development, and Demonstration under grant agreement No. 604434 PneumoNP.

Acknowledgments: We are grateful to the Clinical Pharmacological and Toxicological Laboratory, as well as the Pathology Research Trial Service at the Erasmus University Medical Center, Rotterdam, the Netherlands, for the pharmacokinetic analysis of blood samples and the preparation of histopathological samples, respectively. We would also like to express our appreciation to D. Horst-Kreft and J. den Boer for their technical support, and to H. I. Bax and J. W. Mouton for providing expert perspectives, all from the Department of Medical Microbiology and Infectious Diseases, Erasmus University Medical Center, Rotterdam, The Netherlands.

Conflicts of Interest: The authors declare no conflict of interest. 


\section{Appendix A}
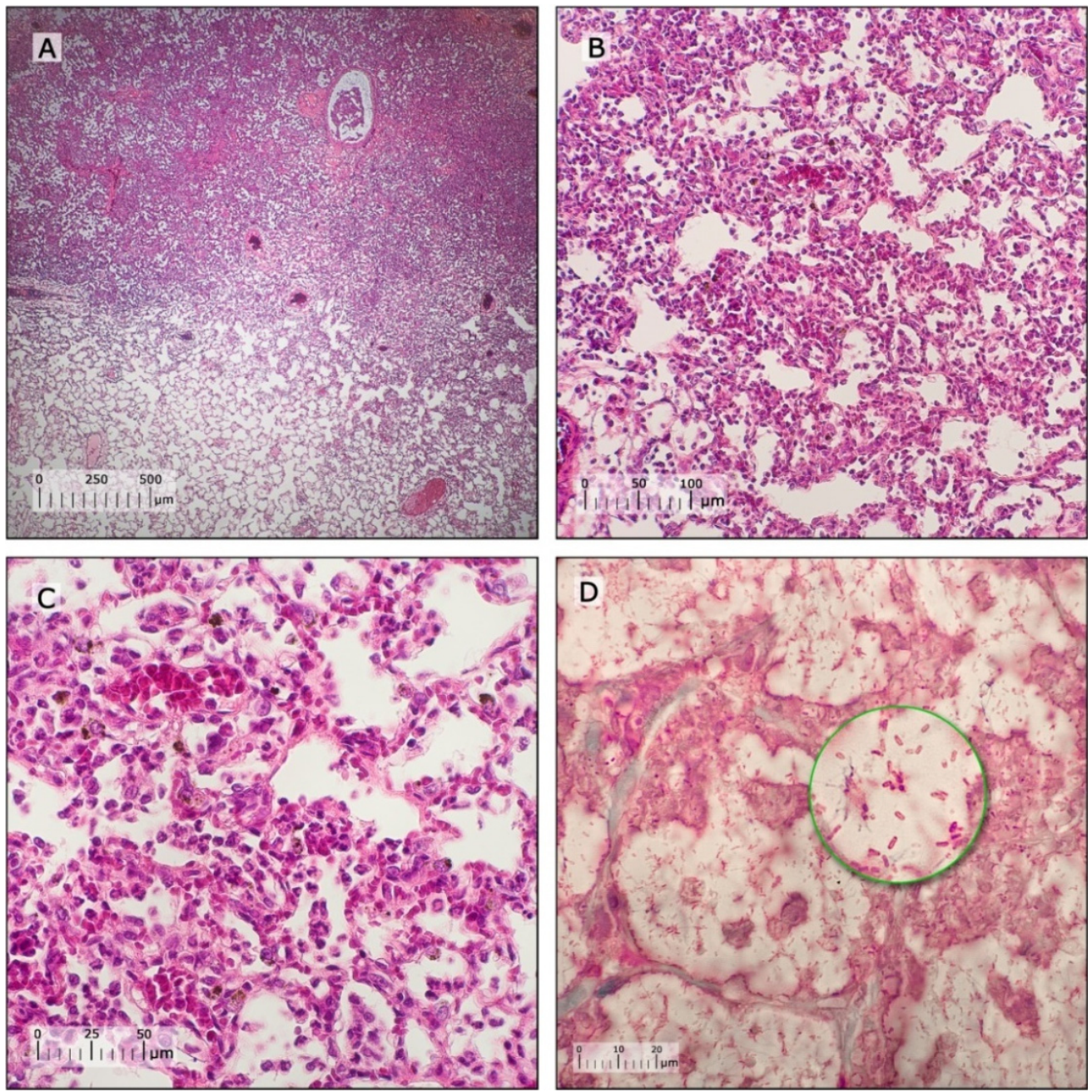

Figure A1. Representative lung histopathology in lung tissue from rats with K. pneumoniae KPC pneumonia-septicemia at $24 \mathrm{~h}$ after initiation of infection. (A-C) Sections stained with hematoxylin-eosin at different magnifications. (D) Section stained with Gram stain. An outer hemorrhagic zone of the lesion was observed (in areas next to uninfected tissue), in which the alveoli were filled with mucoid exudates dominated by edema fluid and a light cellular infiltrate. More extensive areas of pneumonia were observed towards the center of the lesion (i.e., in the zone of early consolidation). In these areas, alveoli were packed with predominantly polymorphonuclear leukocytes and alveolar walls were necrotic. Numerous encapsulated Gram-negative bacilli were freely present in the exudates within the hemorrhagic zone of the lesions.

\section{References}

1. Peleg, A.Y.; Hooper, D.C. Hospital-acquired infections due to gram-negative bacteria. N. Engl. J. Med. 2010, 362, 1804-1813. [CrossRef] [PubMed]

2. Girlich, D.; Poirel, L.; Nordmann, P. CTX-M expression and selection of ertapenem resistance in Klebsiella pneumoniae and Escherichia coli. Antimicrob. Agents Chemother. 2009, 53, 832-834. [CrossRef] [PubMed]

3. Tzouvelekis, L.S.; Markogiannakis, A.; Psichogiou, M.; Tassios, P.T.; Daikos, G.L. Carbapenemases in Klebsiella pneumoniae and other Enterobacteriaceae: An evolving crisis of global dimensions. Clin. Microbiol. Rev. 2012, 25, 682-707. [CrossRef] [PubMed]

4. Duin, D.; Cober, E.D.; Richter, S.S.; Perez, F.; Cline, M.; Kaye, K.S.; Kalayjian, R.C.; Salata, R.A.; Evans, S.R.; Fowler, V.G. Tigecycline therapy for carbapenem-resistant Klebsiella pneumoniae (CRKP) bacteriuria leads to tigecycline resistance. Clin. Microbiol. Infect. 2014, 20, O1117-O1120. [CrossRef] 
5. Temkin, E.; Adler, A.; Lerner, A.; Carmeli, Y. Carbapenem-resistant Enterobacteriaceae: Biology, epidemiology, and management. Ann. N. Y. Acad. Sci. 2014, 1323, 22-42. [CrossRef]

6. Burkhardt, O.; Rauch, K.; Kaever, V.; Hadem, J.; Kielstein, J.T.; Welte, T. Tigecycline possibly underdosed for the treatment of pneumonia: A pharmacokinetic viewpoint. Int. J. Antimicrob. Agents 2009, 34, 101-102. [CrossRef]

7. Cunha, B.A.; Baron, J.; Cunha, C.B. Monotherapy with High-Dose Once-Daily Tigecycline is Highly Effective Against Acinetobacter baumanii and other Multidrug-Resistant (MDR) Gram-Negative Bacilli (GNB). Int. J. Antimicrob. Agents 2018, 52, 119. [CrossRef]

8. The European Committee on Antimicrobial Susceptibility Testing (EUCAST). Guidance Document on Tigecycline Dosing in association with Revision of Breakpoints for Enterobacterales and Other Species with an "Intermediate" Category (December 2018). Available online: http://www.eucast.org (accessed on 2 March 2020).

9. Falagas, M.E.; Vardakas, K.Z.; Tsiveriotis, K.P.; Triarides, N.A.; Tansarli, G.S. Effectiveness and safety of high-dose tigecycline-containing regimens for the treatment of severe bacterial infections. Int. J. Antimicrob. Agents 2014, 44, 1-7. [CrossRef]

10. Heizmann, W.; Löschmann, P.-A.; Eckmann, C.; Von Eiff, C.; Bodmann, K.-F.; Petrik, C. Clinical efficacy of tigecycline used as monotherapy or in combination regimens for complicated infections with documented involvement of multiresistant bacteria. Infection 2015, 43, 37-43. [CrossRef]

11. Goessens, W.H.F.; Mouton, J.W.; Marian, T.; Sörgel, F.; Kinzig, M.; Bakker-Woudenberg, I.A.J.M. The therapeutic effect of tigecycline, unlike that of ceftazidime, is not influenced by whether the Klebsiella pneumoniae strain produces extended-spectrum $\beta$-lactamases in experimental pneumonia in rats. Antimicrob. Agents Chemother. 2013, 57, 643-646. [CrossRef]

12. Bassetti, M.; Welte, T.; Wunderink, R.G. Treatment of Gram-negative pneumonia in the critical care setting: Is the beta-lactam antibiotic backbone broken beyond repair? Crit. Care 2015, 20, 19. [CrossRef] [PubMed]

13. Fasciana, T.; Gentile, B.; Aquilina, M.; Ciammaruconi, A.; Mascarella, C.; Anselmo, A.; Fortunato, A.; Fillo, S.; Petralito, G.; Lista, F. Co-existence of virulence factors and antibiotic resistance in new Klebsiella pneumoniae clones emerging in south of Italy. BMC Infect. Dis. 2019, 19, 928. [CrossRef] [PubMed]

14. Hennequin, C.; Robin, F. Correlation between antimicrobial resistance and virulence in Klebsiella pneumoniae. Eur. J. Clin. Microbiol. Infect. Dis. 2016, 35, 333-341. [CrossRef] [PubMed]

15. Woodford, N.; Fagan, E.J.; Ellington, M.J. Multiplex PCR for rapid detection of genes encoding CTX-M extended-spectrum $\beta$-lactamases. J. Antimicrob. Chemother. 2005, 57, 154-155. [CrossRef]

16. Mabilat, C.; Goussard, S. PCR detection and identification of genes for extended-spectrum $\beta$-lactamases. In Diagnostic Molecular Microbiology: Principles and Applications; American Society for Microbiology: Washington, DC, USA, 1993; pp. 553-559.

17. Nüesch-Inderbinen, M.T.; Hächler, H.; Kayser, F.H. Detection of genes coding for extended-spectrum SHV beta-lactamases in clinical isolates by a molecular genetic method, and comparison with the E test. Eur. J. Clin. Microbiol. Infect. Dis. 1996, 15, 398-402. [CrossRef]

18. Dallenne, C.; Da Costa, A.; Decré, D.; Favier, C.; Arlet, G. Development of a set of multiplex PCR assays for the detection of genes encoding important $\beta$-lactamases in Enterobacteriaceae. J. Antimicrob. Chemother. 2010, 65, 490-495. [CrossRef]

19. Karisik, E.; Ellington, M.J.; Pike, R.; Warren, R.E.; Livermore, D.M.; Woodford, N. Molecular characterization of plasmids encoding CTX-M-15 $\beta$-lactamases from Escherichia coli strains in the United Kingdom. J. Antimicrob. Chemother. 2006, 58, 665-668. [CrossRef]

20. Bradford, P.A.; Bratu, S.; Urban, C.; Visalli, M.; Mariano, N.; Landman, D.; Rahal, J.J.; Brooks, S.; Cebular, S.; Quale, J. Emergence of carbapenem-resistant Klebsiella species possessing the class A carbapenem-hydrolyzing KPC-2 and inhibitor-resistant TEM-30 $\beta$-lactamases in New York City. Clin. Infect. Dis. 2004, 39, 55-60. [CrossRef]

21. Islam, M.A.; Talukdar, P.K.; Hoque, A.; Huq, M.; Nabi, A.; Ahmed, D.; Talukder, K.A.; Pietroni, M.A.C.; Hays, J.P.; Cravioto, A. Emergence of multidrug-resistant NDM-1-producing Gram-negative bacteria in Bangladesh. Eur. J. Clin. Microbiol. Infect. Dis. 2012, 31, 2593-2600. [CrossRef]

22. Boers, S.A.; Van der Reijden, W.A.; Jansen, R. High-throughput multilocus sequence typing: Bringing molecular typing to the next level. PLoS ONE 2012, 7, e39630. [CrossRef] 
23. Souverein, D.; Boers, S.A.; Veenendaal, D.; Euser, S.M.; Kluytmans, J.; Den Boer, J.W. Polyclonal Spread and Outbreaks with ESBL Positive Gentamicin Resistant Klebsiella spp. in the Region Kennemerland, The Netherlands. PLoS ONE 2014, 9, e101212. [CrossRef] [PubMed]

24. Gruteke, P.; Goessens, W.; Van Gils, J.; Peerbooms, P.; Lemmens-den Toom, N.; Van Santen-Verheuvel, M.; Van Belkum, A.; Verbrugh, H. Patterns of resistance associated with integrons, the extended-spectrum $\beta$-lactamase SHV-5 gene, and a multidrug efflux pump of Klebsiella pneumoniae causing a nosocomial outbreak. J. Clin. Microbiol. 2003, 41, 1161-1166. [CrossRef] [PubMed]

25. Padilla, E.; Alonso, D.; Doménech-Sánchez, A.; Gomez, C.; Pérez, J.L.; Albertí, S.; Borrell, N. Effect of porins and plasmid-mediated AmpC $\beta$-lactamases on the efficacy of $\beta$-lactams in rat pneumonia caused by Klebsiella pneumoniae. Antimicrob. Agents Chemother. 2006, 50, 2258-2260. [CrossRef]

26. The European Committee on Antimicrobial Susceptibility Testing (EUCAST). Breakpoint Tables for Interpretation of MICs and Zone Diameters, version 10.0. 2020. Available online: http://www.eucast.org (accessed on 2 March 2020).

27. De Steenwinkel, J.E.M.; De Knegt, G.J.; Ten Kate, M.T.; Van Belkum, A.; Verbrugh, H.A.; Kremer, K.; Van Soolingen, D.; Bakker-Woudenberg, I.A.J.M. Time-kill kinetics of anti-tuberculosis drugs, and emergence of resistance, in relation to metabolic activity of Mycobacterium tuberculosis. J. Antimicrob. Chemother. 2010, 65, 2582-2589. [CrossRef] [PubMed]

28. The European Committee on Antimicrobial Susceptibility Testing (EUCAST). Antimicrobial Wild Type Distributions of Microorganisms, Version 5.26. 2019. Available online: http://mic.eucast.org/Eucast2/ (accessed on 2 March 2020).

29. Balls, M.; Goldberg, A.M.; Fentem, J.H.; Broadhead, C.L.; Burch, R.L.; Festing, M.F.; Frazier, J.M.; Hendriksen, C.F.; Jennings, M.; Van der Kamp, M. The three Rs: The way forward: The report and recommendations of ECVAM Workshop 11. ATLA 1995, 23, 838.

30. Kilkenny, C.; Browne, W.J.; Cuthill, I.C.; Emerson, M.; Altman, D.G. Improving bioscience research reporting: The ARRIVE guidelines for reporting animal research. PLoS Biol. 2010, 8, 100412. [CrossRef]

31. Abdulla, A.; Bahmany, S.; Wijma, R.A.; Van der Nagel, B.C.H.; Koch, B.C.P. Simultaneous determination of nine $\beta$-lactam antibiotics in human plasma by an ultrafast hydrophilic-interaction chromatography-tandem mass spectrometry. J. Chromatogr. B 2017, 1060, 138-143. [CrossRef]

32. Zhang, Y.; Huo, M.; Zhou, J.; Xie, S. PKSolver: An add-in program for pharmacokinetic and pharmacodynamic data analysis in Microsoft Excel. Comput. Methods Programs Biomed. 2010, 99, 306-314. [CrossRef]

33. Hori, T.; Nakano, M.; Kimura, Y.; Murakami, K. Pharmacokinetics and tissue penetration of a new carbapenem, doripenem, intravenously administered to laboratory animals. In Vivo 2006, 20, 91-96.

34. Bradford, P.A. Extended-spectrum $\beta$-lactamases in the 21st century: Characterization, epidemiology, and detection of this important resistance threat. Clin. Microbiol. Rev. 2001, 14, 933-951. [CrossRef]

35. Freire, A.T.; Melnyk, V.; Kim, M.J.; Datsenko, O.; Dzyublik, O.; Glumcher, F.; Chuang, Y.-C.; Maroko, R.T.; Dukart, G.; Cooper, C.A. Comparison of tigecycline with imipenem/cilastatin for the treatment of hospital-acquired pneumonia. Diagn. Microbiol. Infect. Dis. 2010, 68, 140-151. [CrossRef] [PubMed]

36. Duran, F.Y.; Yıldırım, H.; Şen, E.M. A Lesser Known Side Effect of Tigecycline: Hypofibrinogenemia. Turk. J. Hematol. 2018, 35, 83. [CrossRef] [PubMed]

37. Pieringer, H.; Schmekal, B.; Biesenbach, G.; Pohanka, E. Severe coagulation disorder with hypofibrinogenemia associated with the use of tigecycline. Ann. Hematol. 2010, 89, 1063-1064. [CrossRef] [PubMed]

38. Zhang, Q.; Zhou, S.; Zhou, J. Tigecycline treatment causes a decrease in fibrinogen levels. Antimicrob. Agents Chemother. 2015, 59, 1650-1655. [CrossRef]

39. Routsi, C.; Kokkoris, S.; Douka, E.; Ekonomidou, F.; Karaiskos, I.; Giamarellou, H. High-dose tigecycline-associated alterations in coagulation parameters in critically ill patients with severe infections. Int. J. Antimicrob. Agents 2015, 45, 90-93. [CrossRef]

40. Wu, X.; Zhao, P.; Dong, L.; Zhang, X. A case report of patient with severe acute cholangitis with tigecycline treatment causing coagulopathy and hypofibrinogenemia. Medicine 2017, 96, e9124. [CrossRef]

41. Gong, J.; Su, D.; Shang, J.; Yu, H.; Du, G.; Lin, Y.; Sun, Z.; Liu, G. Efficacy and safety of high-dose tigecycline for the treatment of infectious diseases: A meta-analysis. Medicine 2019, 98, e17091. [CrossRef]

42. Cunha, B.A.; Baron, J.; Cunha, C.B. Once daily high dose tigecycline-pharmacokinetic/pharmacodynamic based dosing for optimal clinical effectiveness: Dosing matters, revisited. Expert Rev. Anti-Infect. Ther. 2017, 15, 257-267. [CrossRef] 
43. Baron, J.; Cai, S.; Klein, N.; Cunha, B. Once Daily High Dose Tigecycline Is Optimal: Tigecycline PK/PD Parameters Predict Clinical Effectiveness. J. Clin. Med. 2018, 7, 49. [CrossRef]

44. De Pascale, G.; Montini, L.; Pennisi, M.A.; Bernini, V.; Maviglia, R.; Bello, G.; Spanu, T.; Tumbarello, M.; Antonelli, M. High dose tigecycline in critically ill patients with severe infections due to multidrug-resistant bacteria. Crit. Care 2014, 18, R90. [CrossRef]

45. Geng, T.-T.; Xu, X.; Huang, M. High-dose tigecycline for the treatment of nosocomial carbapenem-resistant Klebsiella pneumoniae bloodstream infections: A retrospective cohort study. Medicine 2018, 97, e9961. [CrossRef]

46. Chen, Z.; Shi, X. Adverse events of high-dose tigecycline in the treatment of ventilator-associated pneumonia due to multidrug-resistant pathogens. Medicine 2018, 97, e12647. [CrossRef]

47. Gao, H.; Yao, Z.; Li, Y.; Huang, S.; Liu, J.; Jing, Y. Safety and Effectiveness of High Dose Tigecycline for Treating Patients with Acute Leukemia after Ineffctiveness of Carbapenems Chemotherapy Combinating with Febrile Neutropenia: Retrospective study [Article in Chinese; spelling errors present in PubMed reference]. Zhongguo Shi Yan Xue Ye Xue Za Zhi 2018, 26, 684-690. [PubMed]

48. Tsala, M.; Vourli, S.; Daikos, G.L.; Tsakris, A.; Zerva, L.; Mouton, J.W.; Meletiadis, J. Impact of bacterial load on pharmacodynamics and susceptibility breakpoints for tigecycline and Klebsiella pneumoniae. J. Antimicrob. Chemother. 2016, 72, 172-180. [CrossRef] [PubMed]

49. Ni, W.; Li, G.; Zhao, J.; Cui, J.; Wang, R.; Gao, Z.; Liu, Y. Use of Monte Carlo simulation to evaluate the efficacy of tigecycline and minocycline for the treatment of pneumonia due to carbapenemase-producing Klebsiella pneumoniae. Infect. Dis. 2018, 50, 507-513. [CrossRef] [PubMed]

50. Lin, Y.-T.; Jeng, Y.-Y.; Chen, T.-L.; Fung, C.-P. Bacteremic community-acquired pneumonia due to Klebsiella pneumoniae: Clinical and microbiological characteristics in Taiwan, 2001-2008. BMC Infect. Dis. 2010, 10, 307. [CrossRef] [PubMed]

51. Lin, Y.-T.; Wang, Y.-P.; Wang, F.-D.; Fung, C.-P. Community-onset Klebsiella pneumoniae pneumonia in Taiwan: Clinical features of the disease and associated microbiological characteristics of isolates from pneumonia and nasopharynx. Front. Microbiol. 2015, 6, 122. [CrossRef]

52. Qureshi, Z.A.; Paterson, D.L.; Potoski, B.A.; Kilayko, M.C.; Sandovsky, G.; Sordillo, E.; Polsky, B.; Adams-Haduch, J.M.; Doi, Y. Treatment outcome of bacteremia due to KPC-producing Klebsiella pneumoniae: Superiority of combination antimicrobial regimens. Antimicrob. Agents Chemother. 2012. [CrossRef]

53. Xie, J.; Roberts, J.A.; Alobaid, A.S.; Roger, C.; Wang, Y.; Yang, Q.; Sun, J.; Dong, H.; Wang, X.; Xing, J. Population pharmacokinetics of tigecycline in critically ill patients with severe infections. Antimicrob. Agents Chemother. 2017, 61, e00345-17. [CrossRef]

54. Nicolau, D.P. Pharmacokinetic and pharmacodynamic properties of meropenem. Clin. Infect. Dis. 2008, 47, S32-S40. [CrossRef]

55. Gilbert, D.N.; Chambers, H.F.; Eliopoulos, G.M.; Saag, M.S.; Pavia, A.T. The Sanford Guide to Antimicrobial Therapy, 47th ed.; Antimicrobial Theraphy, Inc.: Sperryville, VA, USA, 2017.

56. Mouton, J.W.; Touw, D.J.; Horrevorts, A.M.; Vinks, A.A. Comparative pharmacokinetics of the carbapenems. Clin. Pharmacokinet. 2000, 39, 185-201. [CrossRef] [PubMed]

57. Muralidharan, G.; Micalizzi, M.; Speth, J.; Raible, D.; Troy, S. Pharmacokinetics of tigecycline after single and multiple doses in healthy subjects. Antimicrob. Agents Chemother. 2005, 49, 220-229. [CrossRef] [PubMed]

58. Ghazi, I.M.; Crandon, J.L.; Lesho, E.P.; McGann, P.; Nicolau, D.P. Efficacy of humanized high-dose meropenem, cefepime, and levofloxacin against Enterobacteriaceae isolates producing Verona integron-encoded metallo- $\beta$-lactamase (VIM) in a murine thigh infection model. Antimicrob. Agents Chemother. 2015, 59, 7145-7147. [CrossRef] [PubMed]

59. Giannella, M.; Trecarichi, E.M.; Giacobbe, D.R.; De Rosa, F.G.; Bassetti, M.; Bartoloni, A.; Bartoletti, M.; Losito, A.R.; Del Bono, V.; Corcione, S. Effect of combination therapy containing a high-dose carbapenem on mortality in patients with carbapenem-resistant Klebsiella pneumoniae bloodstream infection. Int. J. Antimicrob. Agents 2018, 51, 244-248. [CrossRef]

(C) 2020 by the authors. Licensee MDPI, Basel, Switzerland. This article is an open access article distributed under the terms and conditions of the Creative Commons Attribution (CC BY) license (http://creativecommons.org/licenses/by/4.0/). 